\title{
Sexual health in the South African context
}

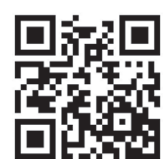

Sexual health is a major area of relevance to global public health. The World Health Organization (WHO) has stipulated that every person has the right to sexual health. ${ }^{[1]}$ The United Nations Educational, Scientific and Cultural Organization (UNESCO) has identified sexual rights and sexual health education and training as a global priority. ${ }^{[2]}$ There is also growing interest in human rights and lesbian, gay, bisexual, transgender and intersex (LGBTI) issues internationally. However, there are few centres of excellence for sexual health in lowand middle-income countries, where the vast majority of the world's population live, and there is a real need to establish such resources.

Recently, the clinical utility and operational criteria of sexual disorders have received some attention in the literature owing to the recent revision of the Diagnostic and Statistical Manual of Mental Disorders to version 5 (DSM-5) and the ongoing revision of the International Classification of Diseases and Related Health Problems to version 11 (ICD-11). Locally, for example, a recent WHO-funded meeting in South Africa explored the clinical utility of proposed revisions to the ICD-11. In August 2013, a team of 20 South African sexual health experts from across health science disciplines met with human rights legal experts and sexual health activists to engage in the first multidisciplinary sexual health collaborative meeting of its kind in South Africa. Its aim was to gain stakeholder input in the development of research protocols for evaluating the clinical utility of ICD-11 revisions in the areas of sexual dysfunction (F52) and gender identity disorders (F64) within the South African context. While considerable expertise in the area of sexual health was identified during this meeting, concerns about limitations in education and training also emerged.

The integrated multidisciplinary model prescribed by UNESCO's sexual health curriculum, in accordance with WHO guidelines, teaches healthcare providers to conduct a robust sexual history with patients presenting with sexual health complaints. ${ }^{[3]}$ This sexual history allows the healthcare provider to: (i) confirm the patient's diagnosis; (ii) evaluate the impact of the distress on the patient's overall health; and (iii) set management goals. When used in combination with a medical history focused particularly on cardiovascular, neurological, urogenital, hormonal and psychological systems, the sexual history provides indicators of aetiology, while establishing comorbid medical conditions and their potential role in sexual dysfunction. A thorough assessment helps with early detection, diagnosis and treatment.

Currently, few South African clinicians receive the necessary training to address sexual dysfunction comprehensively, and there are no accredited South African training programmes in this area. Some of those wishing to specialise in sexual medicine have obtained qualifications abroad. These limited educational opportunities are mirrored in the limited current, original research in the area of sexual health in South Africa. ${ }^{[4]}$ This gap in training and continued professional development in the area of sexual health has implications for clinician confidence when assessing and treating sexual problems in patients in general and in sexual minority groups such as LGBTI patients in particular.

The intention of this editorial and the related CME series is to help generate renewed interest in the area of sexual health and provide practical information to family practitioners on a variety of topics related to sexual health and function. Interested readers wishing to apply a framework for clinical assessment and treatment of patients presenting with sexual dysfunctions are referred to Ramlachan and Campbells ${ }^{[5]}$ review of an integrative, multidisciplinary treatment approach. Boa ${ }^{[6]}$ provides a comprehensive review of female sexual dysfunctions and treatment options, while Ramlachan and Campbell ${ }^{[7]}$ review the epidemiology, clinical assessment and treatment options for male sexual dysfunctions. Campbell and Stein ${ }^{[8]}$ discuss an approach to hypersexual disorder, highlighting the family practitioner's role in patient care, and Wilson et al. ${ }^{[9]}$ outline the role of the Groote Schuur Transgender Unit

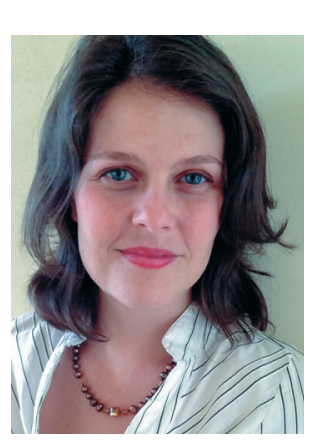
in providing healthcare for South African transgender patients. Geffens' ${ }^{\text {'10] }}$ review of the relationship between sexual functioning and age completes this CME series.

\section{Megan M Campbell}

Counselling Psychologist and Postdoctoral Research Fellow, Department of Psychiatry and Mental Health, Faculty of Health Sciences, University of Cape Town, South Africa

mm.campbell@uct.ac.za

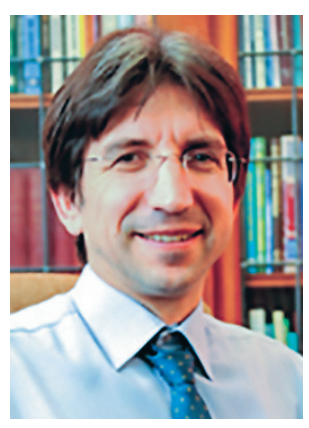

\section{Dan J Stein}

Professor and Head, Department of Psychiatry and Mental Health, University of Cape Town, and Director, MRC Unit on Anxiety and Stress Disorders, Cape Town, South Africa

dan.stein@uct.ac.za

1. Cottingham J, Kismodi E, Hilber AM, et al. Using human rights for sexual and reproductive health: Improving legal and regulatory frameworks. Bull World Health Organ 2010;88(7):551-555. [http:// dx.doi.org/10.2471/BLT.09.063412]

2. United Nations Educational, Scientific and Cultural Organization. The International Technical Guidance on Sexuality Education: An evidence-informed approach for schools, teachers and health educators. Paris: UNESCO, 2009

3. Montorsi F, Adaikan G, Becher E, et al. Summary of the recommendations on sexual dysfunctions in men. J Sex Med 2010;7(11):3572-3588. [http://dx.doi.org/10.1111/j.1743-6109.2010.02062.x]

Campbell MM, Stein DJ. Sexual dysfunction: A systematic review of South African research. S Afr Med J 2014;104(6):440-444. [http://dx.doi.org/10.7196/SAMJ.7827]

5. Ramlachan P. Campell MM. An integrative treatment model for patients with sexual dysfunctions. 5. Ramlachan P, Campbell MM. An integrative treatment model for pati
S Afr Med J 2014;104(6):445. [http://dx.doi.org/10.7196/SAMJ.8374]

6. Boa R. Female sexual dysfunction. S Afr Med J 2014;104(6):446. [http://dx.doi.org/10.7196/SAMJ.8373]

6. Boa R. Female sexual dysfunction. S Afr Med J 2014;104(6):446. [http://dx.doi.org/10.7196/SAMJ.8373]
7. Ramlachan P, Campbell MM. Male sexual dysfunction. S Afr Med J 2014;104(6):447. [http://dx.doi. Ramlachan P, Campbell

8. Campbell MM, Stein DJ. Hypersexual disorder in general practice. S Afr Med J 2014;104(6):448. [http://dx.doi.org/10.7196/SAMJ.8409]

9. Wilson D, Marais A, de Villiers A, Addinall R, Campbell M. Transgender issues in South Africa, with particular reference to the Groote Schuur Hospital Transgender Unit. S Afr Med J 2014;104(6):449. [http://dx.doi.org/10.7196/SAMJ.8392]

10. Geffen L. Sexual function and ageing. S Afr Med J 2014;104(6):450. [http://dx.doi.org/10.7196/ SAMJ.8396]

S Afr Med J 2014;104(6):439. DOI:10.7196/SAMJ.8391 